\title{
COMPLEX GAMIFICATION PLATFORM BASED ON MOODLE SYSTEM
}

\author{
Balázs Barna and Szabina Fodor ${ }^{1}$ \\ ${ }^{l} D r ., P h D$ \\ Corvinus University of Budapest, Hungary
}

\begin{abstract}
Using an e-learning system as an educational tool has become a common practice among university courses. A well-structured e-learning system can not only support the course as a storage place of materials but can help the students to learn the given subjects. The Moodle (Modular Object-Oriented Dynamic Learning Environment) e-learning environment provides a wide scale of possibilities to create a student-centered, highly manageable course interface. The tool is given; however, the motivation of students is rarely satisfying. Tough the success of a course mostly depends on the teaching materials, using gamification principles can enhance the motivation level of students. The aim of this paper is to propose a structure built up from the core elements of Moodle, existing plugins and suggested developments, which could provide a properly gamified Moodle course that fosters the students to gain motivation for learning better.
\end{abstract}

\section{KEYWORDS}

Gamification, Education, e-Learning Platform

\section{GAMIFICATION: MOTIVATIONAL TECHNOLOGY}

For people, learning is a vital ability. Pastor-Pina et al (Pastor-Pina et al, 2015) point out that teachers can create an environment that supports learning, but the learner needs an active role to succeed. Student motivation and commitment are key factors in the learning process.

The gamification (which is the use of game design elements in non-game context (Deterding et al, 2011) combines a certain progress (e.g. work, study) with reward-based design aspects of games to create a product that is enjoyable and motivating as well as productive and efficient (O’Donovan, 2012).

Nacke and Deterding wrote (Nacke and Deterding, 2017) that several companies and design agencies offer gamification design or software-as-a-service (SaaS) packages, and organizations across the globe began exploring gamification to motivate people and improve the user experience. These applications vary between education, training, health, innovation, employee engagement, marketing etc. (Seaborn and Fels, 2015)

Most gamified systems can be built using the following components (Werbach and Hunter, 2012), (Hunicke et al, 2004):

- Game elements: these are the specific elements that the user is already facing when using the game for the first time: collect points, work in team, do some personalization, or perform missions;

- Game mechanisms: they describe how each game element interacts with each other and how the individual steps and states of the user are determined. It also includes guidelines to determine the progress of the game, as well as the expected reactions to an event;

- Game dynamics: these are the behavior of players and their interrelationship triggered by game elements and mechanisms. Dynamics are influenced by the nature and experience of the user. A risk-averse, inward-looking player has a different behavioral pattern than a user who is looking for particularly risky situations;

- Fun: adds the more or less entertaining factor to the application.

In order to create an effective game or game-like application, it must be motivating and addictive as well as providing encouragement to reach short-term goals, meanwhile it maintains the option for making a mistake or fail, along with retrying as long as the user finally succeeds (O’Donovan et al, 2013). 
Considering the source of motivation, there can be intrinsic and extrinsic types from it. Intrinsic motivated users choose and do activities just by curiosity or by their own will. This kind of users are ready to make a significant mental effort during a task, and to use deeper and more effective learning strategies. On the other hand, extrinsic motivated users are only committed to activities when they are externally rewarded (such as getting good marks or avoiding failure). Generally, extrinsic motivation is easier to be created and be managed than intrinsic motivation. (Pastor-Pina et al, 2015) Idealistically, the main goal of using extrinsic motivation solutions is to turn them into intrinsic motivation within the users.

\section{RELATED WORK}

Several researches deal with the issue of enhancing and examining a course built up with e-learning system.

Researchers from Kaunas University of Technology (Jurgelaitis et al, 2018) created a course of 'gamified UML and system design' in Moodle environment using the core elements and a few plugins. As a result, they could report that the students are satisfied with the course, find it useful and they enjoyed the course itself.

Members of University of Alicante made a research (Pastor-Pina et al, 2015) which aim was to analyze the suitability of Moodle to implement structurally gamified teaching proposals in it. The authors stated the environment is 'not quite friendly' to help teachers to use game-elements in their courses. Tough the visual appearance of gamification can be considered as poor, a strong logical system (mainly based on conditions of accessibility of contents) can be used to create different learning paths for students.

In 2015 at Corvinus University of Budapest, an IT course has been rebased into a blended form using the Moodle supporting with gamification components, like points, badges and levels as a reward system, alternative learning paths for different style of learning methods, feedbacks and social interactions. As a result, higher participation rate could be achieved during the semester, and the students valued the gained knowledge more than those who learnt the course in a non-gamified environment. Besides the positive results, the research points out to some restrictions and lack of student-level personalization in Moodle. (Barna and Fodor, 2018).

\section{MOODLE: THE GAMIFICATION PLATFORM}

Common strategy for gamifying an educational course is to migrate to an e-learning environment as a first step and introduce gamification elements as a second step (Jurgelaitis et al, 2018).

Moodle is one of the most used open source learning management systems nowadays, and it is quite popular among teachers because it is free and, they can create their own online courses very easily (Pastor-Pina et al, 2015). The platform provides comprehensive logs about activities done by users on sites, tasks or the course itself (Moodle, 2016), however the satisfaction and motivation cannot be found out from these data.

\subsection{Existing Elements}

In the examined e-learning system several elements and plugins can be. Some of the Moodle's core elements can be useful from the aspect of gamification, such as setting restrictions for accessing documents, parts of a page or tasks. With tracking the completion and restricting the accessibility of activities, different levels can be defined, maps can be set up to explore the content of the course, or even Easter eggs can be hidden. For completing special achievements, badges and titles can be given to the users. With using grade book, the users of Moodle can check their grades and points, which can be handled as a feedback of their progress. Online social interactions can be fostered with forums and chats, and the teachers can measure the knowledge level of students with quizzes, assignments, lessons, workshops or surveys.

The list of gamification related plugins include a module that facilitates progress with a visualized levelling-up, asks back a question bank in the form of a miniature game, makes video materials interactive, implements inventory for students, and has a module that introduces a virtual currency into the course. (Moodle, 2019) 
These plugins contain mostly gamification elements, thus - as mentioned in Chapter 1.1 - an effective gamified application should consist not only gamification elements, but mechanics and game-dynamics as well.

\subsection{Proposed Solution}

Moodle is capable of implementing various gamification elements and partial solutions to a course maker, but it does not help to follow the principles of gamification for the whole course at system level.

By combining the current plugins, the personalized auditing and motivation cannot be realized. Due to the various kinds of users, different motivation ways are needed for them. Motivation may include smaller challenges (e.g. "Practice with tests 5 days in a row for +3 points!"), displaying the progress of student, customizing the graphical interface to allow the user (with limited freedom) to change the appearance of the system (theme of design, theme of levels, etc.).

In this paper, the examined features and functions are separated by their purposes into four categories:

$\begin{array}{ll}\text { 1) serving the main goal (learn and develop) } & 3 \text { ) providing social connections and interactions }\end{array}$

2) fostering the use of service (exploring) 4 4) enhancing the feel of personalization

The following list shows the Core elements, the Existing plugins, and the suggested Additional plugins and improvements (+).

\section{Motivated learning by developing and recognition:}

- The main function of an e-learning system is to provide Knowledge materials of a specific topic in a more or less structured way. Using a Content Map helps the students to overlook the amount and connections of the required materials. Even with an existing plugin, these materials can be enhanced into Interactive materials (e.g. attached multimedia, checking quiz whether the student understands the given knowledge or not).

- The Moodle system provides several kinds of Tasks which can measure the knowledge level of a student. Using Mini Games(+) as a way of practicing can make the course more interesting, but they can make the course light-minded if they are overused or they do not fit into the topic.

- With completing the tasks, the students can earn Points; with their accumulating points, they can achieve higher Levels(+) and better final Grades.

- Beside finishing a task or fill out a test, additional Rewards(+) can be set which can be used to foster proper preparation of a student, or recognize the student's learning progress (e.g. giving new color-schema). The final Goal of a course is achieving a high grade, but Minor goals should be set as well. If the course is separated into several parts, the sub-goals can be the completion of them. In order to inform the student, Progress Bar can be used to show the current completion state of the selected (minor) goal.

Motivated learning by engaging and exploring:

- Moodle allows to create Knowledge materials as lessons, sub-pages, contents by default. With the help of Access management, parts of the material-collections can be restricted to certain conditions (which depend on the actions of a student), such as completing a Task, or collecting a preset amount of Points.

- In order to motivate students to do (or at least check) several not mandatory tasks, assignments or tests, Challenges can be set up or Badges(+) can be given (e.g. for visiting all tasks).

- For those who are keen on exploring as much details of the site as possible, collectable Easter Eggs(+) can be hidden, therefore they have the urge to visit every part of the course.

Motivated learning by social connections and interactions:

- Social interactions take an important role in gamification. The Moodle provides possibilities to use Forum and Chat for sharing information between users.

- Assignments that requires Teamwork can also be attached to a course by default.

- Two-way communication between students and teachers is not well-supported by the core functions, but with the possibility to give Feedback to teachers, the students could $\underline{\text { Rate }}$ the tasks and materials.

Motivated learning by personalization:

- The Moodle cannot give opportunity for user-level Personalization within a course, the established environment is valid for every student. With giving the opportunity for changing the appearance of the interface (e.g. color-schema, $\underline{\text { Theme }}$ of levels) to users, it can give them the feel of personalization. 
- Based on the activated materials and completed tasks, $\underline{\text { Personalized test }}$ can be created automatically for the students that helps to maintain and improve their knowledge.

There are some highly gamified components that can be hardly applied in Moodle due to the visual structure of interface or due to the nature of teaching, such as storytelling, using different emotions, or forcing a leaderboard on students.

\section{CONCLUSIONS AND FURTHER WORK}

The use of e-learning systems takes significant role in university education. Besides providing technical environment, the urge to use them by students must be fostered as well. For this purpose, the authors suggest applying gamification principals, therefore the motivation for learning can be enhanced.

In this paper the Moodle e-learning environment has been examined in order to find out how well it is appropriate for gamifying a course with it. After examining the existing parts of Moodle, a proposed solution has been described which combinates the core elements of Moodle, the already created plugins for it and some suggested developments. The proposed concepts are aligned by how they can foster the motivated learning: by developing and recognition, by exploring, by social interactions and by personalization. The course creators can decide which of the mentioned flows and concepts they can apply for their course, and which part of the concepts should be developed.

As for further work, the authors plan to develop some of the not yet existing plugins (Sub-goals and Progress Bar), apply them in a course, and examine their effect.

\section{ACKNOWLEDGEMENT}

This article has been supported by the ÚNKP-18-3 New National Excellence Program of the Hungarian Ministry of Human Capacities.

\section{REFERENCES}

Barna, B. and Fodor, Sz., 2018. An Empirical Study on the Use of Gamification on IT Courses at Higher Education. In: Teaching and Learning in a Digital World. ICL 2017. Advances in Intelligent Systems and Computing. Vol 715. Springer, Cham

Deterding, S. et al, 2011. From Game Design Elements to Gamefulness: Defining "Gamification", MindTrek '11 Procee-dings of the 15th International Academic MindTrek Conference: Envisioning Future Media Environments, pp. 9-15.

Hunicke, R. et al, 2004. MDA: A Formal Approach to Game Design and Game Research. Nineteenth National Conference on Artificial Intelligence, http://www.cs.northwestern.edu/ hunicke/MDA.pdf

Jurgelaitis, M. et al, 2018. Gamified Moodle Course for Teaching UML. Baltic J. Modern Computing, Vol. 6(2), pp. 119-127, at: https://doi.org/10.22364/bjmc.2018.6.2.03

Moodle, 2016. Logs, at: https://docs.moodle.org/37/en/Logs, accessed: 2019. 06. 20.

Moodle, 2019. Gamification - A list of plugins that brings some aspects of gamification to Moodle courses., at: https://moodle.org/plugins/browse.php?list=set\&id=88, accessed: 2019. 05. 30.

Nacke, L. E. and Deterding, S., 2017. The maturing of gamification research. Computers in Human Behavior, White Rose University Consortium, at: http://dx.doi.org/10.1016/j.chb.2016.11.062

O'Donovan, S., 2012. Gamification of the Games Course, at: http://pubs.cs.uct.ac.za/archive/00000771/01/ Gamification_of_the_Games_Course, accessed: 2019.01.11.

O’Donovan, S., Gain, J., Marais, P., 2013. A case study in the gamification of a university-level games development course, pp. 242, at: http://dl.acm.org/citation.cfm?id=2513456.2513469

Pastor-Pina, H. et al, 2015. Can Moodle be used for structural gamification? INTED2015 Proceedings, pp. 1014-1021, at: https://www.sun.ac.za/english/learning-teaching/ctl/Documents/Can moodle be used for structural gamification.pdf

Seaborn, K., and Fels, D. I., 2015. Gamification in theory and action: A survey. International Journal of Human-Computer Studies, Vol. 74(2), pp 14-31. at: http://doi.org/10.1016/j.ijhcs.2014.09.006

Werbach, K. and Hunter, D., 2012. For The Win. How Game Thinking Can Revolutionize Your Business. Wharton Digital 